\title{
Pakistan Agriculture and Livestock: An Insight and Climate Change Impacts
}

\author{
Muhammad Mansoor ${ }^{1}$, Roshan Zada ${ }^{2}$, Muhammad Jamil ${ }^{3}$, Muhammad Kashif ${ }^{4}$, Shahid \\ Hameed Khan Khalil ${ }^{5}$, Zafar Islam ${ }^{6}$ and Muhammad Adeel Ahmad ${ }^{7}$ \\ ${ }^{1}$ Plant Sciences Division, Pakistan Agricultural Research Council, Islamabad-44000 Pakistan \\ ${ }^{2}$ Pakistan Agricultural Research Council, Islamabad-44000-Pakistan \\ ${ }^{3,7}$ PARC Arid Zone Research Center, Dera Ismail Khan-29050-Pakistan \\ ${ }^{4}$ Department of clinical sciences,sub campus Jhang, University of \\ Veterinary and animal sciences, Lahore, Pakistan, Lahore 54000, Pakistan \\ ${ }^{5,6}$ Climate, Energy and Water Research institute, National Agricultural Research \\ Center, -Islamabad-54000-Pakistan \\ Corresponding author email: joyadkpk@googlemail.com
}

\section{ABSTRACT}

This review article focuses on Impacts of Climate Change and their Effects on Agriculture and livestock in Pakistan. In this article we were studied that the related literature to present topic in a good and better way and also discussed the climate change impacts and adaptation strategies in agriculture and livestock sector. Climate and agriculture are directly connected to one another so I found it good on talk about the summer season, winter season and monsoon season and their impact on agriculture in Pakistan. This article will also provide a short study of undernourished people in Pakistan as well as a graph that explains this theory in a better way. The way to overcome the shortcomings of bad climate effect on agriculture and livestock is also discussed in this paper because various climatic conditions, such as average temperature, humidity, and wind speed, play a significant impact in the fertility, reproductive performance, meat and milk output of dairy cows. From all this review. In conclusion the Pakistan is one of the most climate-sensitive nations despite contributing just 0.8\% to atmospheric Greenhouse Gases (GHG) More than 40\% of the population in this region is involved in agricultural production. Pakistan has inadequate water storage facilities and aging water infrastructure.

KEY WORDS: CLIMATE, AGRICULTURE, PAKISTAN.

\section{INTRODUCTION}

Agriculture is one of the most vulnerable sectors of the economy to climate change. It reacts to climate change-related changes in temperature, precipitation, and soil radiation. In overpopulated areas of the world, rising temperatures, uneven rainfall distribution, floods, droughts, and other climatic calamities have had an impact on human existence and socio-economic sectors

Biosc Biotech Res Comm P-ISSN: 0974-6455 E-ISSN: 2321-4007

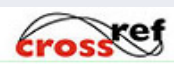

Identifiers and Pagination

Year: 2021 Vol: 14 No (9) Special Issue

Pages: $321-329$

This is an open access article under Creative

Commons License Attribn 4.0 Intl (CC-BY).

DOI: $h t t p: / / d x$.doi.org/10.21786/bbrc/14.9.59 (ie, South Asia). Assessing the eventual economic impact of climate change on agricultural producers, consumers, and other factors necessitates a thorough examination of the economic impact utilizing data from several climate and crop models. Scientists and crop experts collaborated on a thorough study to investigate the potential consequences of climate change. They analyzed the interaction of meteorological variables using multiple physical, biological, and chemical principles, and then estimated their reaction to rising amounts of greenhouse gas emissions in the atmosphere using global climate models.

Agricultural facilities account for about 20\% of the rise in man-made greenhouse gas emissions each year. Carbon dioxide $\left(\mathrm{CO}_{2}\right)$, methane $\left(\mathrm{CH}_{4}\right)$, and nitrous oxide (NOx) emissions from the industry contribute to global warming $\left(\mathrm{N}_{2} \mathrm{O}\right)$. Greenhouse gases allow light to reach the

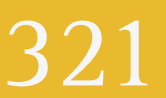


ground while preventing heat transfer and attempting to escape from the atmosphere, collecting heat in the same way as a greenhouse does. $\mathrm{CH}_{4}$ has around 300 times the global warming potential of $\mathrm{CO}_{2}$ and about 20 times the potential of $\mathrm{N}_{2} \mathrm{O}$. Nitrogen fertilizer, flooded rice fields, soil management, land conversion, biomass burning, livestock production, and related manure management are the main sources of gas. The livestock industry contributes between $5 \%$ and $10 \%$ of the total greenhouse gas emissions.

The Asia-Pacific area has seen extreme heat in recent decades. The agricultural industry is especially sensitive in these regions, accounting for 37 percent of total world emissions from agricultural production in Asia and the Pacific. Bhutan, Indonesia, Pakistan, Papua New Guinea, the People's Republic of China, Sri Lanka, Thailand, East Timor, Uzbekistan, and Vietnam are the country's most vulnerable to climate change (Asian Development Bank, 2009). On the other side, the agriculture industry has the potential to harm the environment. Paul et al. were the ones that came up with this solution (2009). The agricultural sector is responsible for 14 percent of nitric oxide and methane emissions, with deforestation for agricultural purposes accounting for 18 percent. In the agricultural sector, season and location are critical factors in output. African crops are more sensitive to minor temperature fluctuations than they are to rainfall changes. Rising temperatures benefit African crops, whereas less rainfall has a negative impact on net revenue. These findings are based on 300 South African regions and seven African field crops (maize, wheat, sorghum, sugarcane, peanuts, sunflowers, and soybeans) (Gbetibouo, 2005). The study also revealed that agricultural growth seasons can shift in response to temperature, although this behavior could result in the extinction of specific crops in particular places.

Pakistan is one of the most climate-sensitive countries, despite contributing only 0.8 percent of global greenhouse gas emissions. Pakistan is ranked 135th among other countries. Pakistan was ranked seventh most susceptible country in the 2017 Global Climate Risk Index due to its geographic and climatic characteristics. It is situated in a geographical region where temperature rises are predicted to be greater than the world average. The glacier, which is the river's primary source of food, is fast receding, and the majority of the land is barren or semi-arid. Agriculture employs more than 40\% of the inhabitants in the region. Their vulnerability is exacerbated by the fluctuation of monsoon rains, largescale floods, and droughts. The combined influence of all of these climatic factors puts the country's food, water, and energy security in jeopardy.

The output of Pakistan's principal grain crops is prone to high temperatures and poor rainfall, according to empirical literature based on crop models. In Pakistan, the growing season necessitates a specific quantity of heat and precipitation. During the wheat growing season, the average temperature remains mild. Despite this, wheat does not receive enough rain to thrive. After the monsoon, irrigation water and rainfall restore the majority of the arable land. According to the 2016-17 Pakistan Economic Survey, canal water irrigates 30\% of total arable land area for wheat crops, while tube wells and other sources irrigate 55 percent. However, only 15\% of the population has access to water.

The range and extent of monsoon rainfall has reduced over time as a result of climate change. The summer monsoon is responsible for $60 \%$ of all annual precipitation. Pakistan is also a water-scarce country, with limited water storage facilities and old water supply infrastructure, including a vast irrigation network. Although there is a growing body of literature on the impact of climate change on crop yields in Pakistan, the nature and scope of its economic impact remains largely unknown. Furthermore, there is a scarcity of study on the effects of agricultural impacts on human livelihoods. The majority of present research focuses on the local equilibrium analysis of climate change variables (such as temperature and precipitation) on crop yields and production.

An Overview of Climate Change and Agriculture in Pakistan: When it comes to climate change, Pakistan is no exception. Pakistan is particularly sensitive to climate change due to its geographic location. It is situated in an area where the likelihood of temperature rise is expected to be higher than the global average. Pakistan's agricultural lands are mostly arid or semi-arid. According to meteorological statistics, around $60 \%$ of the whole area receives yearly precipitation of less than $250 \mathrm{~mm}$, while $24 \%$ receives annual precipitation of 250 to $500 \mathrm{~mm}$. The Indus River is the principal source of agricultural water, with the Karakoram, Himalayas, and Hindu Kush glaciers supplying the majority of it. Recent studies, however, have convincingly demonstrated that these glaciers are fast melting as a result of climate change. Pakistan's economy is highly vulnerable to climate change because it is based on agriculture. Because of this vulnerability, the monsoon rainfall fluctuations that resulted in the 2010 drought and flood represent a significant hazard.

Under light of these topographical facts, insufficient water supply, food security, and electricity generation are clearly in jeopardy (TFCC, 2010). Pakistan has a land area of 79.61 million hectares, excluding the northern section of the country. Only 72 percent of the total area has been recorded, indicating that 28 percent of the region has still to be surveyed for land use classification. The total area provided is divided into four categories: forest (4.02 million hectares), uncultivated land (22.88 hectares), arable land (8.12 hectares), and crops (22.05 hectares). If enough water is available, approximately 8.1 million hectares of the total reported area can be exploited for future agricultural and other uses (Ahmad and Joyia, 2003). Agriculture and animal husbandry have long been the backbones of the economy, contributing roughly 22\% of GDP, 60 percent of exports, 68 percent of the population's livelihoods, and 44 percent of the overall workforce's employment. 
Climate Change Impacts and Adaptation strategies in Agricultural Sector: The scientific community has come to the conclusion that climate change is occurring. Climate change is occurring worldwide, according to the IPCC's fifth report. Developing countries are projected to suffer disproportionately more losses than developed countries. Two main choices for societal reaction have arisen in order to handle the repercussions of climate change: mitigation and adaptation. Mitigation and adaptation, according to Fusel, are complementary rather than mutually exclusive. Historically, mitigation measures have been the primary focus of efforts to combat climate change. However, a shift has occurred, and it is now widely accepted that mitigation alone will not be adequate to address climate change. Climate change adaptation has gotten a lot of attention in scientific and political issues. "The adjustment of ecological, social, or economic systems in response to real or expected climate stimuli and their affects or effects," according to the definition of adaptation. "Adaptation is vital to reduce vulnerability to climate change and is the only way to deal with the unavoidable repercussions of the coming decades," according to Stern. Many countries have already put in place national, provincial, state, regional, and local strategies to deal with climate events on various levels.

At the Seventh Conference of the Parties in Morocco in 2001, the predicament of developing countries was acknowledged for the first time. Climate change adaptation's critical significance as a policy has been properly explored and acknowledged internationally. Article $4.1 \mathrm{~b}$ of the United Nations Framework Convention on Climate Change, for example, states that the parties "commit to formulate and implement national programmes, and as appropriate, regional programmes, which include measures to mitigate climate change and measures to promote full adaptation to climate change." Similarly, the Kyoto Protocol's Article 10 promotes the development of adaptation and the incorporation of adaptation technological advancements to combat climate change. Furthermore, the necessity to increase the adaptation measures of the Parties to the Convention (UNFCCC) was stressed during the 2007 UN Climate Change Conference in Bali.

To avoid the effects of climate change, adaptation is required; else, the effects will be gradual. Climate models suggest that disastrous floods, torrential rains, and heat waves will become more common. As a result, such climate impact scenarios must be factored into adaptation plans. Adaptation is viewed as a promising first step toward improving local capacity to respond to both expected and unanticipated weather events. Climate change adaptation is a key component of the 2015 Paris Agreement. Dessai et al (2005) believe that mitigation alone will not be sufficient to address climate change effectively. As a result, efforts are being made all across the world to adapt to the challenge of climate change. Pakistan understands the necessity of climate change adaptation. In order to address Pakistan's climate change problem, it is necessary to develop a change adaption strategy (Ali et al. 2017). Adaptation measures are a priority in Pakistan's policy response. The national climate change policy, for example, focuses on climate adaption measures. Given Pakistan's significant sensitivity to climate change, Mumtaz feels that climate adaptation measures are unavoidable. These adaptation efforts, according to reports, are critical for all key industries, including agriculture.

Pakistan's status as a developing country makes it highly reliant on agriculture, making it particularly sensitive to climate change. The agricultural industry alone contributes for 21\% of GDP and 44\% of the labor force. The agriculture sector, which provides for around 65 percent of foreign exchange, is also very important to the country's exports. More over two-thirds of the country's population lives in rural areas, with agricultural and agriculture-related industries providing the majority of their income (Pakistan, 2009). The agriculture sector's contribution to GDP, exports, and employment has decreased dramatically. Climate change is thought to be the primary cause of agricultural production decline, in addition to other factors.

"In 2009, the Pakistani government drew attention to the fact that the agricultural sector had underperformed in 2007-08. In contrast to the aim of $4 \%$, it climbed by 1.5 percent. The agricultural sector was hit hard in May 2007 due to a variety of factors, including heavy rain, high temperatures in August and September 2007, and a lack of water during the irrigation season. The current research topic Punjab is Pakistan's second-largest and densely populated province. Punjab's main economic activity is agriculture. The agricultural sector dominates the majority of Punjab's land (57.2 percent). It also accounts for over 53\% of Pakistan's agricultural GDP (Punjab, 2009). According to the Punjab Development Statistics for 2007-08, released in 2009, Punjab's primary crops contribute 59.1 percent of rice, 74.5 percent of wheat, 63.1 percent of sugar cane, 74.5 percent of corn, and 77.8 percent of cotton to the country's agricultural production. Similarly, when it comes to key fruits, Punjab produces a significant portion of the country's total output.

Climate change and disaster: Climate change also brings climate variability/extreme weather events, which can be measured over a shorter period of time. Climate variability (extreme weather events) has increased in recent years, resulting in hydro meteorological disasters, which are a major problem around the world. Storms, floods, droughts, and hurricanes have been common in recent years around the world, claiming lives and livelihoods and exacerbating poverty. Climate variability and the frequency of extreme events are increasing in Pakistan, and they are the primary cause of climate disasters. The frequency of hydro meteorological disasters has increased worldwide, particularly in Pakistan, since the 1990s. Because of its climatic and geographic diversity, the country is vulnerable to these climatic disasters. The fragile sector (agriculture) accounts for a large portion of our economy, and the majority of the 
rural population is impoverished. The level of resistance is low. Given that one of the most serious consequences of climate change is increased climate variability, which increases the risk of extreme weather events and hydro meteorological disasters, it is critical to work on climate change adaptation and disaster risk reduction. Extreme weather events pose a risk of disaster.

\section{Climate Change, Agricultural Adaptation and Fairtrade:} Climate change will have an impact on many Fairtrade export crops, including cotton, cocoa, coffee, tea, sugar, bananas, flowers, and citrus. Crop yields may increase or decrease as a result of climate change, and planting places may shift. These changes, however, are difficult to assess or forecast. Returns may be harmed (positive and negative effects may occur in different time periods and in different locations). The areas and thresholds that can be cultivated will alter as the climatic average (temperature and precipitation) changes. Although there are more and more evaluations on the potential influence of climate change on agriculture and agricultural product trade, they are still largely limited to the primary grains of wheat, rice, and corn, with the impact on fair trade not thoroughly studied. This study was commissioned by the Fairtrade Foundation to help the fair-trade movement adapt to the issues that climate change offers to fair trade producers.

Concept of Fairtrade: Fair trade is a business partnership built on communication, transparency, and mutual respect. It aspires to make international trade more equitable. It encourages long-term growth by improving economic conditions and protecting the rights of underprivileged producers and workers. The International Fair Trade Labeling Organization (FLO) has a number of procedures or "paths of influence" for fair trade certification. It tries to have a positive impact on disadvantaged workers and producers through various processes or "paths of influence" (Eberhart and Smith, 2008). They include producer and trader standards, auditing and certification of producer organizations and farms based on these standards, and fair trade organizations' capacity-building networks and advocacy operations. Technical aid, organizational development assistance, skills training, and more capable ways to create trust and help less powerful groups define their own narratives and agendas are all examples of capacity building.

Climate change impacts on smallholder agriculture: Long-distance and remote climate change impacts may arise when the influence of climate change affects a population, prompting them to adopt adaptations (modifications and more radical alterations) in order to have an impact in another region. This could happen as a result of market forces or population shifts, for example. There will be secondary consequences as a result of the government's, development agencies', non-governmental organizations', and private sector's responses. In the future of climate reduction, adaptation, and development, new political frontiers have developed (Boyd et al., 2009), but it needs to be seen whether climate policies and plans will provide new prospects for low-carbon development and a better environment.

Is causing or exacerbating existing social and environmental inequity. have been observed social inequality may increase if adaptation and mitigation measures are not implemented in a gender-sensitive way, and full participation of women and socially excluded groups in key policies and decision-making is not increased (Nelson et al. 2002; 2017; FAO, 2007; Dan Kerman, 2008). Given the unpredictability and severity of climate change estimates, trade-offs in adaptation decision-making must be explored as decision-making gets increasingly complex. Who will hear opinions in decision-making will be more crucial than ever, and marginalized groups will require more help to engage in the adaptation policy process?.

Climate and Fairtrade Crops: As we all know, atmospheric greenhouse gases (mostly carbon dioxide, $\mathrm{CO}_{2}$, and water vapour, $\mathrm{H}_{2} \mathrm{O}$ ) trap long-wave radiation, causing the earth's temperature to rise by around 30 degrees Celsius (Jain, 2009). However, since the 1980s, people have understood that the amount of $\mathrm{CO}_{2}$ in the atmosphere has increased as a direct result of human activity, from a pre-industrial (1750) level of c. $280 \mathrm{ppm}$ to a present level of c. 388 ppm (Houghton, 2009; NOAA, 2010). In the twentieth century, this resulted in an average temperature increase of $0.6{ }^{\circ} \mathrm{C}+/-0.2{ }^{\circ} \mathrm{C}$, mainly during the 1980 s (IPCC, 2007). Because there are different scenarios for the speed and nature of economic growth, the increase in greenhouse gas emissions and different climate models give different results, it's difficult to predict the future of global warming. However, everyone agrees that as the level of carbon dioxide rises, so will the amount of carbon dioxide in the atmosphere. The planet will become warmer if it continues to climb (IPCC, 2007). In the next two decades, global temperatures are expected to rise by at least $0.2^{\circ} \mathrm{C}$ every decade. Even if greenhouse gas and aerosol emissions remain unchanged after this time, the temperature is anticipated to climb by at least $0.1^{\circ} \mathrm{C}$ per ten years. However, a model indicates that by 2100 , the temperature will have risen to $6^{\circ} \mathrm{C}$, with disastrous ecological effects (IPCC, 2007).

According to the model's forecasts, variations in temperature and rainfall will be significant, with some areas becoming warmer and others becoming colder. Likewise, certain areas will be more humid, while others would be dryer. These changes will modify the length of the growing season, which might have a significant impact on corn and other crop output in regions of Africa. The decline of snow cover in the Himalayas will have an impact on the water flow of certain major river systems in Asia, restricting irrigation water supplies. Sea level rise will impair rice and other crop output due to salt water intrusion, while temperature and precipitation patterns will change the scope and productivity of crops separately or in combination. Fields that are more complicated but also more complex. It's usually written in the negative. These are the results of direct crop physiology effects. Crop pest and disease transmission 
will also change as a result of these changes, altering the dynamics of these interactions (Harrington and Woiwod, 1995; Bale et al. 2002). The order of relative importance of these effects is a source of debate in the scientific literature.

The impact of climate change on feed crop production: Agriculture and food supply stability, in addition to natural vegetation, are the most vulnerable activities to climate and meteorological changes. Unfavorable climatic conditions can result in a considerable fall in crop yields, and in certain cases, crop extinction. To avoid this, significant efforts are needed to investigate the adaptive capacity of crops. It is critical to adjust production technologies to planting site conditions and crop requirements, expand the usage of drought-resistant varieties/hybrids, and apply selective breeding to achieve these aims. One possible effect of climate change is the need to transition as much as possible from production based on natural precipitation to production based on irrigation. The soil moisture development model gives quick information on how soil water supply conditions match the needs of various crop kinds, expressed as a percentage of the maximum useable water content of the soil. Several studies in temperate regions have come to the same conclusion that a $10 \%$ reduction in precipitation will raise irrigation water demand by at least $7-8 \%$, however crop kinds and climatic circumstances play a role. Many significant data points in the literature point to the need of distinguishing between prospective and actual vegetation periods. The possible vegetative season will be extended as a result of the higher average daily temperature.

Higher temperatures, on the other hand, cause rapid growth, which shortens the life cycle of crops, and hence the duration of the real vegetation period. In this instance, it is more practical to plant types with longer growing seasons (which provide bigger yields and can be stored well) or to grow after harvest. The latter situation allows for the harvesting of the same area twice in the same year (Babinszky et al. 2011). C3, C4, and CAM photosynthesis are the three forms of photosynthesis (Crassulaceae acid metabolism). C3 photosynthesis is the most common type of photosynthesis seen in plants. C4 and CAM photosynthesis are the outcome of drought adaptation because they boost water use efficiency. Furthermore, CAM plants can conserve energy and water in times of scarcity, whereas C4 plants, unlike C3 plants, may perform faster photosynthesis in the desert due to their usage of biochemical pathways. To minimize light respiration, extra and unique anatomy is used.

Cattle production: milk production, milk quality and beef production: Various climatic conditions, such as average temperature, humidity, and wind speed, play a significant impact in the fertility, reproductive performance, and milk output of dairy cows, as well as other species. Has a great deal of genetic potential. The ideal temperature for cows is between 5 and 15 degrees Celsius. Animals begin to sweat at temperatures above $15^{\circ} \mathrm{C}$, but they can still maintain a balance between heat generation and dissipation. Sweating and heat dissipation increase over time. The cow can no longer maintain heat balance at such a high temperature, even though it becomes quite strong over the crucial temperature $\left(25^{\circ} \mathrm{C}\right)$.

According to Cazer et al (2002), the amount of water lost through evaporation on hot days can equal or even exceed the amount of water expelled in milk. The high rate of water loss highlights the need of providing water to cows in hot weather. However, as humidity rises, the body's cooling efficiency diminishes due to water evaporation loss. It is advised to utilize the Temperature and Humidity Index (THI) as an indicator of hot climate conditions $(\mathrm{THI}=0.72(\mathrm{~W}+\mathrm{D})+40.6$, where $\mathrm{W}$ is the wet bulb and D is the dry bulb temperature in ${ }^{\circ} \mathrm{C}$ ). The associated heat stress is mild, moderate, or severe when THI is in the range of $72-80,80-90$, or $90-98$. The dry matter intake and milk production of dairy cows will be negatively affected by an increase in ambient temperature (from $25^{\circ} \mathrm{C}$ to $32^{\circ} \mathrm{C}$ ) and THI (from $73^{\circ} \mathrm{C}$ to $82^{\circ} \mathrm{C}$ ) (West et al. 2003). According to relevant evidence, the shorter an animal is exposed to heat stress, the better its tolerance, yet even modest heat stress might affect its productivity.

Effect of Heat Stress on Dairy Animals in Pakistan: The most significant impacts of heat stress are alterations in energy metabolism and distribution and reduction in DMI. As a result, milk output is reduced. Maintenance energy requirements and heat stress increased by 20$30 \%$ in commercial dairy herds, whereas DMI reduced by 10-20\%. (Chase, 2006). To optimize the milk production response, the formula for providing appropriate food intake for heat-stressed cows relies on improving nondegradable rumen protein. As the temperature rises, so should the amount of forage available (West, 1999). De Rensin and Scaramuzzi (2003) discovered that dairy cows' appetite and dry matter intake are reduced after delivery, prolonging the negative energy phase.

According to Tao et al. (2011), heat stress cooling can increase milk production (28.9 vs. $33.9 \mathrm{~kg} /$ day) while lowering milk protein levels (3.01 vs. 2.87 percent). It's possible that physiological alterations in milk production during heat stress are related to liver glucose being used for processes other than milk synthesis (Baumgard et al. 2011). Temperature, rainfall frequency, and the severity of extreme events all have an impact on livestock and crop output (Thornton et al. 2008). The Humidity and Temperature Index (THI) has been utilized as a heat stress indicator. The THI threshold is 72 (Igono et al. 1992), and a 2009 study by Dikeman and Hanson found that dry bulb temperature can also be used to forecast nursing Holstein cows' rectal temperature in subtropical conditions. Heat load exceeding the neutral heat zone has an impact on animal performance.

To maintain a consistent temperature, animals do not produce excessive heat (West, 1999). Mukherjee and colleagues Heat-stressed cows' lymphocytes were shown to be reduced in 2011. The rectal temperature and respiratory rate will rise physiologically as the ambient 
temperature rises above the thermal neutral zone (Chase, 2006). Estrus hormones are low during heat stress, according to Gwazdauskas (1985), resulting in a shorter estrus duration. He also looked at the poorer fertility of heat-stressed male cattle as a result of changes in spermatogenesis and testosterone after high-temperature exposure. Baumgard and Rhoads (2007) indicated that heat stress has a negative influence on numerous dairy product parameters including milk production and reproduction, producing a major economic burden. The efficiency of reproduction will be reduced as the heat load rises (Fuquay, 1981, Imtiaz Hussain et al. 1992). Most reproductive difficulties are shortened duration and intensity of estrus (Her et al. 1988), lower conception rates (Stott et al. 1972), and significant embryonic death (Wise et al., 1988).

Awareness campaign in Punjab: The Punjab government has launched a climate change and agriculture awareness campaign. They established a radio station to provide weather updates to farmers. Multiple programmes are broadcast on the radio to promote farmer awareness of climate change, its influence on the agricultural industry, and potential solutions to problems. The radio station's influence has been well-documented across the province. Many farmers, for example, listen to the radio on a regular basis to learn about weather conditions, upcoming events, and how climate change may affect them. Some interviewees said they listen to the radio frequently because it provides them with useful information such as weather forecasts, fertilizer and seed application techniques, and government subsidy programmes for agricultural regions. Climate specialists and agricultural experts were asked to examine climate change, its influence on agriculture, and potential remedies in some projects. A farmer informed us that he listens to these programmes on the radio frequently because they provide him with new ideas and best practices from agricultural specialists. Table 1 lists adaptation initiatives as well as the variables that drive them.

A short analysis of how to overcome the shortcoming of bad effects of climate on agriculture: The impact of climate change on agriculture in Pakistan and Asia is a major concern for the people living in the areas affected by it. As per the recent studies, the areas that are receiving the most rainfall have been found to be mostly arid. This means that there will be less or even no rainfall during the summers. This can dramatically affect the productivity of crops. Thus, the governments of most countries including Pakistan are trying to lessen the effects of climate change on their agriculture as much as possible. Pakistan has an agricultural system based on rice. The change in climatic conditions will greatly impact this. There are two types of rice cultivation in Pakistan-organic and the non-organic. Rice is one of the major crops that have been very affected by the change in climate. The crops such as wheat and maize cannot grow properly in areas that receive less rainfall.

Agriculture in Pakistan is also largely dependent on monsoon rains. The monsoon brings heavy rainfall to different parts of Pakistan. The impact of climate change on agriculture in Pakistan can greatly aggravate the problem. As the country receives less rainfall, the fruits and vegetables produced recover slowly and thus have less nutrients. The impact of climate change on agriculture in Pakistan is alarming. However, it is not something which can be immediately acted upon. More studies are required to find out the impacts, both adverse and beneficial, of climate change. The problem is not unique to Pakistan. Across the world, experts are grappling with similar problems.

Experts believe that it will take at least 40 years before the impact of climate change on agriculture in Pakistan can be measured through scientific research. But there is already enough evidence to show that the impact of climate change is felt. An analysis by the International Food Products Corp (IFPC) found that food prices have risen more than fourfold in the past 15 years in Pakistan. In the agricultural sector this means lower production, higher input cost and increased use of agricultural chemicals. Reduced production and high input costs mean that the benefits of increased farming output cannot be realized.

Pakistan climate change impacts and their possible solutions: One important step is to make use of green technologies to reduce greenhouse gas emissions and hence climate change impacts. For example, farmers can increase the efficiency with which they grow plants by using new techniques and technology. Increasing crop rotation techniques, using fertilizers and pesticides in a more appropriate way and using conservation tillage are some of the methods that can be adopted. Using these methods, the impact of climate change on can be reduced up to two thirds.

There is also a need for developing a regional agricultural strategy that takes into account the impact of climate change on agriculture in Pakistan and develops policies that will mitigate the damage. This is a two-way effort as developing regional solutions that are applicable to rural and urban development is only possible if federal government policies are implemented at the national level. Similarly for the developed world there is a need to provide technical assistance to developing countries to build up the necessary capacity and infrastructure required for adaptation. This should include the use of green technologies to reduce greenhouse gas emissions.

All these challenges require urgent action. The impact of climate change on agriculture in Pakistan can be reduced by developing an agricultural policy that taking all these issues into consideration. The key is to start the discussion at the community level, both within Pakistan and with the outside world. This is a step that I believe is necessary for the world's attention to be focused on the problem of climate change and how it is going to impact us all.

Undernourished people in Pakistan: A study: Pakistan's 
economy is based on agriculture due to the agricultural sector's contribution to the country's total income. The agriculture sector employs 42.3 percent of rural population and accounts for 19.8 percent of the country's GDP (GDP). The agricultural sector's major purpose is to increase productivity in order to ensure food security and eliminate poverty. The country is very vulnerable to climate change due to its geographic location, massive population, and lack of technological resources. The 2010 floods cost Pakistan more than $\$ 15$ billion in economic losses, displaced around 300,000 individuals, and badly impacted more than 20 million people. To counteract the detrimental consequences of climate change, Pakistan needs \$6-14 billion every year.

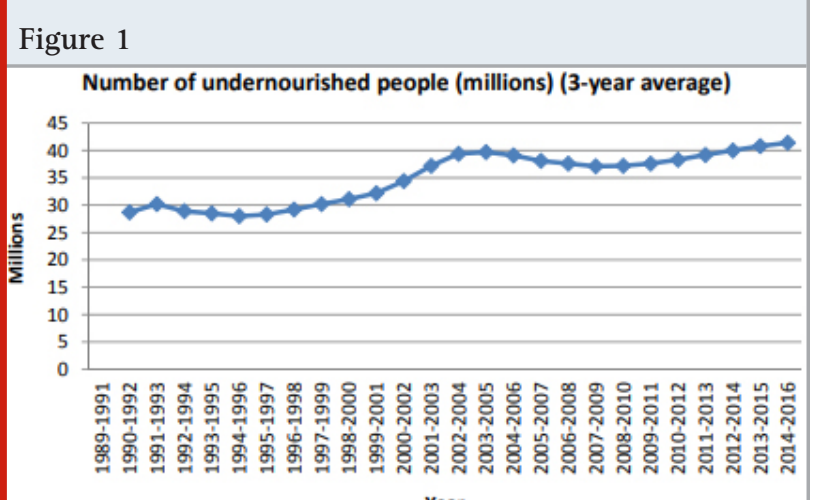

Year

\begin{tabular}{|c|c|c|}
\hline Numbers & Adaptation initiatives & Drivers behind the initiatives \\
\hline 1 & Awareness campaigns & $\begin{array}{l}\text { To educate farmers, control damages, improve productivity, linkage } \\
\text { with NGOs }\end{array}$ \\
\hline 2 & $\begin{array}{l}\text { Training programs for } \\
\text { farmers }\end{array}$ & $\begin{array}{l}\text { To expedite implementation, enhance understanding of farmers, to } \\
\text { prepare the farmer's community for climate change }\end{array}$ \\
\hline 3 & Research and innovation & $\begin{array}{l}\text { Understanding of climate change dynamics, to produce novel } \\
\text { techniques }\end{array}$ \\
\hline 4 & Institutional capacity & $\begin{array}{l}\text { Effective implementation of climate policies, to address the } \\
\text { challenge of lack of professionalism }\end{array}$ \\
\hline 5 & Role of academics & $\begin{array}{l}\text { Better research environment, promote climate research, } \\
\text { establishment of climate policies with sound scientific backing }\end{array}$ \\
\hline 6 & $\begin{array}{l}\text { Departmental } \\
\text { coordination }\end{array}$ & $\begin{array}{l}\text { To expedite implementation mechanism, comprehend the situation } \\
\text { well in time }\end{array}$ \\
\hline 7 & Autonomous adaptation & $\begin{array}{l}\text { Past experiences, knowledge sharing, avoid damages and enhance } \\
\text { productivity }\end{array}$ \\
\hline
\end{tabular}

Floods in 2013, 2011, and 2010, harsh droughts in 19992003, and hurricanes in Karachi/Gwadar in 2008 that caused landslides and glacial lake flooding in northern Pakistan (GLOFS) are just a few of the gifts that climate change has bestowed on Pakistan. Climate change poses a severe danger to Pakistan's food, water, and energy security since weather patterns may alter, extreme events such as floods, droughts, and heat waves may occur, and agricultural production may drop. Pakistan has around 5,000 glaciers that are disappearing at a quicker rate than the rest of the world. Pakistan is one of the world's countries with the highest rate of food insecurity, with approximately 65 percent of the population living in poverty. Congo, China, India, Indonesia, Pakistan, Ethiopia, and Bangladesh are among these countries. Many Asian and African countries have severe food insecurity and are unable to take meaningful measures to address the issue. They also won't be able to meet the Millennium Development Goals or the objective of ending hunger. Figure 1 depicts the number of Pakistanis that are malnourished.

Analysis on crop production in Pakistan in the summer season: Analysis on crop production in Pakistan in the summer season is one of the most important and complex tasks of a government or private organization. With the availability of irrigation and climatic conditions, there are many issues to be tackled at this time. The climate is quite hot during the summer season and it can cause a lot of problem for the farmers who have acres of land. The weather conditions in the country have been pretty stable all through the year. However, the summer season has witnessed a change with frequent heat waves and heavy rainfall. In this era of globalization, analysis on crop production in Pakistan is also getting more difficult due to the huge influx of new technologies and farming techniques from various countries. Some of the places have seen a complete transformation of their whole agricultural production system. Agriculture is not a very old industry in Pakistan and it was developed long back. Agriculture has always been one of the main industries of Pakistan. There are a wide range of crops that are cultivated in this country.

The most popular crops that are grown in Pakistan are wheat, pulses, lentils, ground apple, tea, jute and oranges. All these crops have their own unique history and are cultivated in different regions of the country. The production of pulses is mostly done on farms and smallscale. The major crops grown in the urban areas are rice and wheat. The analysis on crop production in Pakistan in the summer season considers the productivity of each of the above crops as per the weather, climatic conditions and other factors. The analysis on crop production in Pakistan focuses on the productivity of wheat and its yield. This is because of the fact that Pakistan itself has a great wheat-growing region. The yield of wheat is very high and is sold the world market. It is one of the staple foods of the people living in urban areas. The analysis on crop production in Pakistan shows that there is a remarkable development in the production and quality of wheat.

The analysis also indicates that there has been a notable improvement in the production of rice. Both rice fields are being farmed at better levels and the yields are also expected to grow in the coming season. The most important crop, wheat, has seen some fluctuations in the past but it is growing steadily and shows a marked improvement. There is a sharp rise in the demand for wheat in rural areas, though this is declining in the urban regions. Analysis on crop production in Pakistan also indicates that there is a steep increase in the production of oranges.

Analysis on crop production in Pakistan also indicates that there is a marked improvement in the production of tomatoes. There is an increase in the production of both tomatoes (red and green varieties) in the coming 
season. Moreover, an increasing number of farmers have been encouraged to take up cultivation of strawberries. This is because of their popularity. Moreover, the prices of strawberries have been touching the sky in the recent times. The production of coffee and tobacco has also seen a significant improvement in the coming season.

Analysis on crop production in Pakistan also indicates that there has been a marked improvement in the production of onions. The main reason behind this is the improvement in irrigation and soil management. This is helping farmers in getting more harvests from the soil. The improvement in irrigation techniques has helped in irrigation for agricultural lands. This has facilitated the growth and harvest of onions. An analysis on crop production in Pakistan also indicates that there has been improvement in the production of tomatoes and peppers.

The analysis also indicates that there has been an improvement in the production of crops like potatoes and carrots. It has also been noticed that there has been a significant improvement in the productivity of crops in the southern part of the country. These results are largely attributed to the seasonal changes and climatic conditions prevailing in this region. With the right kind of irrigation systems and intensive planting programs, it is expected that the productivity of the agricultural products will improve as the summers draw to a close. Analysis on crop production in Pakistan in the winter season: Analysis on crop production in Pakistan in the winter season reveals that the deficient areas are also supplied with a sufficient amount of rainfall during the monsoon season. This is a great gain for the farmers, as it gives them ample time to complete the harvest. Analysis on crop production in Pakistan in the winter season also reveals the importance of irrigation by using water tank irrigation systems. The government has adopted an effective irrigation system named "Pakbarat". This irrigation system regulates the flow of water in water tanks and provides ample amount of water to the crops.

Analysis on crop production in Pakistan in the winter season also indicates that there is a deficit in the production of pulses. The main culprit is the insecurity of the climate and weather in different parts of the country. During monsoon months, the soil here becomes saline which does not allow adequate amount of moisture to pass through the soil. During the rainy season, the soil here drains off completely. So, in order to ensure productivity in the fields, it is important that irrigation is adopted at proper times.

Analysis on crop production in Pakistan in the winter season also reveals that irrigation improves the productivity of the crops. This is done through channeling the water through sprinklers so that the surface of the soil is moisturized. During the hot climatic conditions, the soil here receives an increased amount of water as compared to other climatic conditions. Analysis on crop production in Pakistan in the winter season also indicates that during the monsoon season, the demand for pulses is on the higher side as compared to the other seasons. It also indicates that due to climatic conditions, farmers are finding it difficult to manage the crops on a large scale. So, in order to overcome this problem, irrigation is provided on a smaller scale during the monsoon season and this has led to an increase in the production. Analysis on crop production in Pakistan in the winter season also indicates that due to adequate rainfall, there is an increase in the yield.

\section{CONCLUSION}

Agriculture and livestock is one of the most climatevulnerable industries. It reacts to climate change-related changes in temperature, precipitation, and soil radiation. Temperature, rainfall frequency, and the severity of extreme events all have an impact on livestock and crop output. The heat stress has a negative influence on numerous dairy product parameters including milk production and reproduction, producing a major economic burden. The efficiency of reproduction will be reduced as the heat load rises. Collaborative and extensive research was undertaken by scientists and crop professionals. They employed a global climate model that analyses meteorological factors using physical, biological, and chemical concepts. The Asia-Pacific area is the most vulnerable to climate change's effects. Pakistan is one of the most climate-vulnerable countries, despite emitting only 0.8 percent of global greenhouse gas emissions (GHG). Agriculture employs more than $40 \%$ of the inhabitants in the region.

Pakistan is a water-scarce country due to a lack of water storage facilities and aged water supply infrastructure. Wheat, beans, lentils, apple powder, tea, jute, and oranges are the most popular crops in Pakistan. In certain locations, the entire agricultural production system has undergone a total shift. Pakistan has a vast wheat-growing region, and wheat is one of the most common meals consumed in urban areas. Wheat demand is increasing in rural areas, whereas it is decreasing in urban areas. Orange production has also expanded dramatically, according to the data. The relevance of adopting tank irrigation systems for irrigation is revealed by a research of winter crop yields in Pakistan. The government devised a costeffective irrigation technology known as "Pakbarat." The flow of water in the tank is controlled by this irrigation system, which provides a significant amount of water to the crops.

\section{ACKNOWLEDGEMENTS}

All authors are highly thankful to the concern institutes.

Conflict of Interest: Authors declare no conflict of interest.

\section{REFERENCES}

Asian Development Bank (ADB) (2009). Building climate resilience in the agriculture sector in Asia and in the 
Pacific. Asian Development Bank, Annual Development Report, p. -9.

Ahmed, M. N., P. M. Schmitz (2011). Using the Ricardian Technique to Estimate the Impacts of Climate Change on Crop Farming in Pakistan. In The EAAE 2011 congress, Zurich, (Vol. 30).

Ali S., Y. Liu, M. Ishaq, T. Shah, A. Ilyas, I.U. Din (2017). Climate change and its impact on the yield of major food crops: Evidence from Pakistan. Food 6(6):39.

Baumgard L.H., J.B. Wheelock, S.R. Sander, C.E. Moore, H.B. Green, M.R. Waldron and R.P. Rhoads (2011). Post absorptive carbohydrate adaptations to heat stress and monensin supplementation in lactating Holstein cows. J. Dairy Sci 94(11):5620-33.

Boyd, E., N. Grist, S. Juhola, V. Nelson (2009). 'Theme Issue: Development Futures in a Changing Climate' Chaudhary, R. C., J.S. Nanda, D.V. Tran (2002). "Guidelines for Identification of Field Constraints to Rice Production”, International Rice Commission, Food and Agriculture Organization of the United Nations, Room Climate Change on Agriculture: Empirical Evidence from Arid Region. Pak. J. Agri. Sci 48(4), 327-333.

Dankelman, I (2002). 'Climate change: learning from gender analysis and women's experiences of organizing for sustainable development'. Gender and Deve. 10 (2) 21-29.

De Rensis, F. R.J. Scaramuzzi (2003). Heat stress and seasonal effects on reproduction in the dairy cow-A review. Theriogenology. 60(6):1139-51.

Dessai S., X. Lu, J.S. Risbey (2005). On the role of climate scenarios for adaptation planning. Glob. Env. Ch15(2):87-97.

Eberhart, N., S. Smith (2008). 'A methodological guide for assessing the impact of Fairtrade' prepared for FLO international

Fuquay, J.W. 1981. Heat stress as it affects animal production. J. Anim. Sci. 52:164.

Füssel H-M (2007). Adaptation planning for climate change: Concepts, assessment approaches, and key lessons. Sus. Sci 2:265-275.

Gbetibouo G.A., R.M. Hassan (2004). Measuring the economic impact of climate change on major South
African field crops. Global and Planetary Change 47:143-152.

Gwazdauskas F.C (1985). Effects of climate on reproduction in cattle. J. Dairy Sci. 68(6): 1568-78.

Harrington R., I.P. Woiwod (1995). Insect crop pests and the changing climate. Weather, 50: 200-208.

Her E., D. Wolfenson, I. Flamenbaum, Y. Folman, M. Kaim, A. Berman (1988). Thermal productive and reproductive responses of high yielding cows exposed to short term cooling in summer. J. Dairy Sci. 71:1085.

IPPC (2007). Intergovernmental Panel on Climate Change, Fourth Assessment Report.

Jain A (2009). Global warming and climate change science. Chapter 11 in Hewitt, C.N. and Jackson, A.V. (eds): Atmospheric Science for Environmental Scientists. Xiii+ 300 pp, Wiley-Blackwell, Chichester

Mendelsohn R., W. Nordhaus, D. Shaw (1994). The impact of global warming on agriculture: A Ricardian analysis. The American Economic Review 84:753771.

Nelson D., N. Adger, K. Brown (2007). Adaptation to Environmental Change: Contributions of a Resilience Framework. Annual Review of Environment and Resources 32, 395-419.

Schlenker W., M. J. Roberts (2006). Nonlinear Effects of Weather on Corn Yields. Review of Agricultural Economics, 28(3): 391-398.

Schlenker W., W. M. Hanemann, A. C. Fisher (2004). Will US Agriculture Really Benefit from Global Warming? Accounting for Irrigation in the Hedonic Approach.

Stern (2006). Stern review on the economics of climate change, H.M. Treasury.

Stott G., H.F. Wiersma, J.M. Woods (1972). Reproductive health program for cattle subjected to high environmental temperatures. J. Am. Vet. Med. Assoc. 161:1339.

TFCC-Task Force on Climate Change: Planning Commission, Government of Pakistan. Available from: http://pc.gov.pk/usefull_links/ Taskforces/TFCC_Final_ Report.pdf.

Wise M.E., D.V. Armstrong, J.T. Huber, R. Homer, F. Wiersma (1988). Hormonal alterations in the lactating dairy cows in response to thermal stress. J. Dairy Sci. 71:2480. 